\title{
Modified dose intensive R- CODOX-M/IVAC for HIV-associated burkitt (BL) (AMC 048) shows efficacy and tolerability, and predictive potential of IRF4/MUM1 expression
}

\author{
Ariela Noy ${ }^{1 *}$, Lawrence Kaplan ${ }^{2}$, Jeannette Lee ${ }^{3}$, Ethel Cesarman ${ }^{4}$, Wayne Tam ${ }^{4}$ \\ From 13th International Conference on Malignancies in AIDS and Other Acquired Immunodeficiencies \\ (ICMAOI)
}

Bethesda, MD, USA. 7-8 November 2011

\section{Background}

HIV associated BL remains of concern for toxicity of dose-intensive regimens used in HIV negative patients (pts). Less intensive regimens have a high relapse rate. We modified CODOX-M/IVAC hoping to preserve efficacy while improving tolerability, particularly treatment related mortality (TRM). Primary object: improving 1 year overall survival (OS) from the historical 65 to $85 \%$.

\section{Methods}

Modifications of the US NCI regimen include rituximab (R), cyclophosphamide reduction $[800 \mathrm{mg} / \mathrm{m} 2 \times 2$ days], vincristine $2 \mathrm{mg}$ cap, methotrexate $(\mathrm{mtx}) 3000 \mathrm{mg} / \mathrm{m} 2$, dual chemotherapy lumbar punctures and IVAC infusion (high risk pts). Antibiotic prophylaxis \& growth factor support specified, $100 \%$ grade IV hematopoietic toxicities in the original regimen. HAART therapy at the discretion of the local MD. Pathology review included CD20, CD10, BCL2, BCL6, p53, Ki67, BLIMP1, IRF4/ MUM1 and EBV EBER. (Table 1)

\section{Results}

Accrual of 33 planned pts by April 2010. Baseline: Classical Burkitt, 97\%; Low/High Risk, 9/91\%; Median (range) Age 42 (19 - 55); CD4 count 195 (0 - 721), CD4 <100, ${ }^{5}$ (27\%); HIV viral load 1819 (Undetectable - 1,187,968). Median follow up (fu) is 9 mos for surviving pt. Number of pts with gr3/4 toxicity: any 20 (61\%), 13 (39\%) hematologic,

* Correspondence: noya@mskcc.org

${ }^{1}$ Memorial Sloan-Kettering Cancer Center, New York, NY, USA

Full list of author information is available at the end of the article
16 (48\%) infection including 7 febrile neutropenia, 6 metabolic with 1 tumor lysis syndrome, 4 neurologic, 2 thrombotic and 1 each coagulation, GI or pain. Only 2 gr $1 / 2$ stomatitis/mucositis; 0 had gr 3/4. Six deaths: encephalopathy with hepatic failure, hepatitis B and pneumonia (1), disease progression (3) including 1 in the CNS; fungal infection (1); HIV. Median 1 year OS ( $\mathrm{n}=34)$ was $81.7 \%$ $(61.0 \%, 92.1 \%)$ with a 35 mo median survival. OS by nonBL defining proteins: EBER +/- (8/16) and p53 +/- (10/10) were not predictive. IRF4/MUM1 +/- $(8 / 15)$ highly predictive in overall pts, but not in the confirmed Burkitt $+/$ (6/14) with only 1 IRF4/MUM1 neg pt dying of BL.

\section{Conclusions}

AMC 048 with a median fu of 9 mos has a 1 yr OS of $82 \%$ in BL. Relapses after 1 year are rare. TRM was zero. $\mathrm{R}$ did not appear to increase toxicity. Only 5 pts withdrew due

\section{Table 1}

\begin{tabular}{cc}
\hline Status & $\mathrm{N}(\%)$ \\
\hline Treatment Completed per protocol & $21(62 \%)$ \\
Disease Progression & $3(9 \%)$ \\
Early termination due to adverse event* & $5(15 \%)$ \\
Early termination due to patient withdrawa ${ }^{* *}$ & $2(6 \%)$ \\
Early termination - counts did not recover within time frame & $1(3 \%)$ \\
to begin cycle 4 & \\
Treatment ongoing & $2(6 \%)$ \\
\hline
\end{tabular}

*1 pt with grade (gr) 4 thrombocytopenia and gr 3 infection; 1 pt with gr 3 left hemiparesis; 1 pt with gr 3 confusion unrelated to treatment; 1 pt with prior hepatitis B and cirrohosis had gr 3 encephalopathy and pulmonary infiltrates; 1 pt with gr 4 neutropenia and gr4 thrombocytopenia.

**1 CR 2 yrs post treatment. 
to AEs. Grade 3/4 toxicities were markedly reduced. Results compare favorably with 2 studies of HIV neg pts. Magrath (1995) reported 100\% grade 4 hematologic and $20 \%$ grade 4 mucositis in 39 adults, 33 children $(92 \% 2 \mathrm{yr}$ EFS). MRC/NCRI LY10 trial (Mead 2008) reduced mtx (3gr/m2), but reported 9\% TRM (64\% 2 yr OS). IRF4/ MUM1 deserves further study in BL.

\section{Acknowledgements}

This study is presented on behalf of the AIDS Malignancy Consortium.

\section{Author details}

${ }^{1}$ Memorial Sloan-Kettering Cancer Center, New York, NY, USA. ${ }^{2}$ University of California, San Francisco, San Francisco, CA, USA. ${ }^{3}$ University of Arkansas for Medical Sciences, Little Rock, Little Rock, AR, USA. ${ }^{4}$ Weill Cornell Medical College and New York Presbyterian Hospital, New York, NY, USA.

Published: 19 April 2012

doi:10.1186/1750-9378-7-S1-014

Cite this article as: Noy et al:: Modified dose intensive R- CODOX-M/ IVAC for HIV-associated burkitt (BL) (AMC 048) shows efficacy and tolerability, and predictive potential of IRF4/MUM1 expression. Infectious Agents and Cancer 2012 7(Suppl 1):014.

Submit your next manuscript to BioMed Central and take full advantage of:

- Convenient online submission

- Thorough peer review

- No space constraints or color figure charges

- Immediate publication on acceptance

- Inclusion in PubMed, CAS, Scopus and Google Scholar

- Research which is freely available for redistribution

Submit your manuscript at www.biomedcentral.com/submit 